\title{
RESULTS WITH ABDOMINAL RESECTION IN HIRSCHSPRUNG'S DISEASE*
}

\author{
BY \\ F. REHBEIN and H. VON ZIMMERMANN \\ From the Surgical Department of the Children's Hospital, Bremen
}

For six years we have been practising abdominal resection for Hirschsprung's disease. The method is also known as segmental resection, anterior resection or State operation.

The operative technique has, apart from certain small alterations, always remained the same. In the application of this procedure certain aspects have been revealed which are important for the theoretical interpretation of the disease and also have practical significance, no matter which method is considered the best.

We need not go into the fundamental work of Swenson and Bodian. Swenson himself presented his views in detail five years ago at the first meeting of the British Association of Paediatric Surgeons, and Ehrenpreis (1955) lectured on Hirschsprung's disease in the newborn infant at the same time.

In 1951 and 1952 we operated on our first cases according to Swenson's method (Swenson and Bill, 1948) and it occurred to us at that time that a dissection of the rectum might possibly lead to a disturbance of sexual potency, to incontinence and to disturbances in evacuation of the bladder. For this reason we switched to the State operation in 1953. Meanwhile it has been proved that this anxiety was unfounded. Swenson (1957) reported that eight patients who had been treated surgically had become fathers and that six others, all over 20 , had no disturbance of potency. Wyllie (1957) reported that, among the large number of patients from the Great Ormond Street Hospital, hardly any lasting disturbances of bladder function had been observed. Incontinence of faeces usually disappears after some time. Only Hiatt $(1958 b)$ reports lasting troubles in $16 \%$. Injury to the pelvic vegetative nerves can however only be avoided if the dissection of the rectum is made close to the wall of the bowel. As Swenson himself says, this part of the operation is time-consuming and difficult. But

\footnotetext{
* A paper read at a meeting of the British Association of Paediatric Surgeons held in Liverpool in June, 1959.
}

this difficulty disappears when the intra-abdominal method is used. Thus it is simpler and can easily be withstood by weak infants. Only the simplicity of this procedure therefore induces us to keep on using it.

Fig. 1 shows that the majority of cases were operated on between the ages of 6 and 12 months.

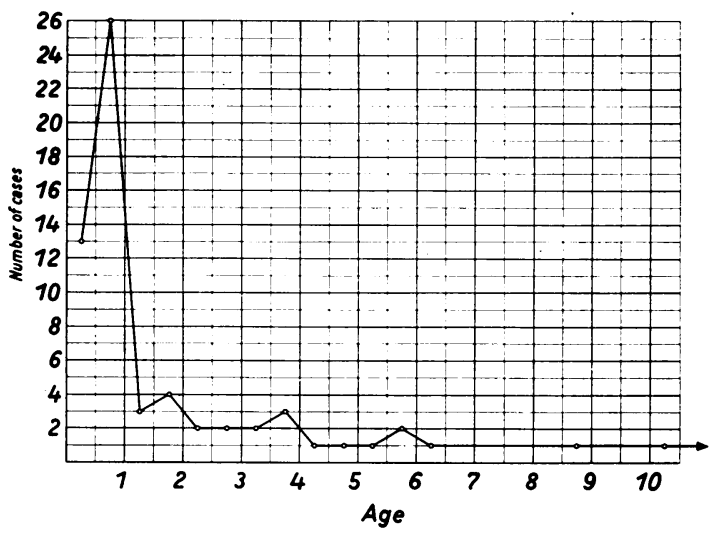

FIG. 1.-Age (yr.) of children at time of operation.

From 1953 to 1958,67 children were operated on in this way. In 56 cases there was the typical finding of a narrow segment.

In 11 cases there was no narrow segment. These cases belong to the megarectum group. Pathological examination disclosed absence of ganglion cells at the lower portion of the resected bowel.

In 60 of the 67 cases treated surgically the diagnosis was confirmed histologically. In seven cases there was no complete aganglionosis. Besides large nerve trunks occasional ganglion cells were found throughout various sections of the lower end of the specimen. We took these cases to be Hirschsprung's disease also. 


\section{Operative Technique}

In abdominal resection the upper rectum is cut through. The resection either involves the sigmoid alone or more often extends to the splenic flexure. In 1952 State pointed out that in most cases the rectum, although aganglionic, is wide or at least distensible. In dissection of the upper rectum it can very often be seen how the narrow segment becomes somewhat wider in the lower direction. The level of the transection is about $1 \mathrm{~cm}$. below the pelvic peritoneal floor (Fig. 2). This level is still easy to reach from an abdominal incision. The distance of the anastomosis from the anus varies according to

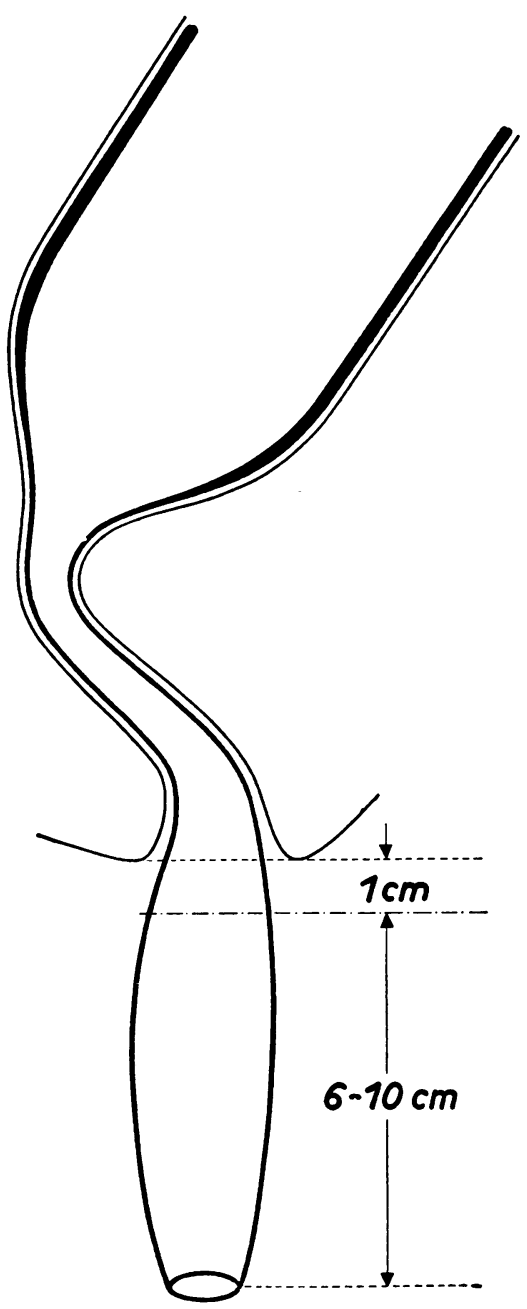

Fig. 2.-Level of transection is situated in upper rectum $1 \mathrm{~cm}$. below pelvic peritoneal floor. Distance from anus varies from $6-10 \mathrm{~cm}$. the age of the child, and the peritoneal floor is sometimes lower, sometimes a little higher. It is about $6-10 \mathrm{~cm}$. and can always be touched by the finger. The whole sigmoid at least must be removed. The wide lumen and the hypertrophied wall are not suitable for anastomosis. In addition resection of the sigmoid eliminates a reservoir in which faeces can accumulate. When the dilatation extends into the descending colon, we have resected as high as the splenic flexure. Even when the resection is extended to the splenic flexure, both lumina are not usually the same size, but the wall is no longer hypertrophic. Care must be taken in anastomosis to ensure that the surplus of the wide lumen is evenly distributed over the narrow lumen (Fig. 3). In the few Hirschsprung cases which had a wide aganglionic rectum but no narrow segment the problem was reversed. We always perform the anastomosis with an open bowel without clamps. A slight soiling of the operational area cannot always be avoided; breakdown of the suture, infection or peritonitis have never occurred. In a large number of cases the anastomosis remains wide and can only be felt as a fine scar. The colon and rectum eventually attain the same calibre. In other cases a slight sickle-shaped projection exists to one side or all round. Occasionally a moderate or serious stenosis has occurred. Then part of the evacuation pressure is lost. But for the success of the operation it is conditional that the anastomosis is wide.

\section{Achalasia}

In one of the first cases which was operated on in this way five years ago abdominal distension and constipation recurred two years later (Fig. 4). Examination revealed that there was no stenosis of the suture. The remaining rectum had expanded. The ampulla was filled with soft faeces. After a vigorous sphincter dilatation and washouts, evacuation started again and the abdominal dilatation disappeared. This child has had no stool difficulties for three years.

It is very interesting that Thomas (1958) describes the same findings in two cases treated by rectosigmoidectomy. This observation, which we also made in other children, is important and suggests that in a case of so-called recurrence the cause is a disturbance of anal function, of the evacuation reflex. Probably it is impossible for the sphincter to relax, in other words an achalasia; or, instead of a relaxation, a contraction occurs. This disturbance of co-ordination must already exist before the operation. But as long as there is a narrow segment this disturbance does not appear so clearly, as it is concealed by the narrow segment. It may be 

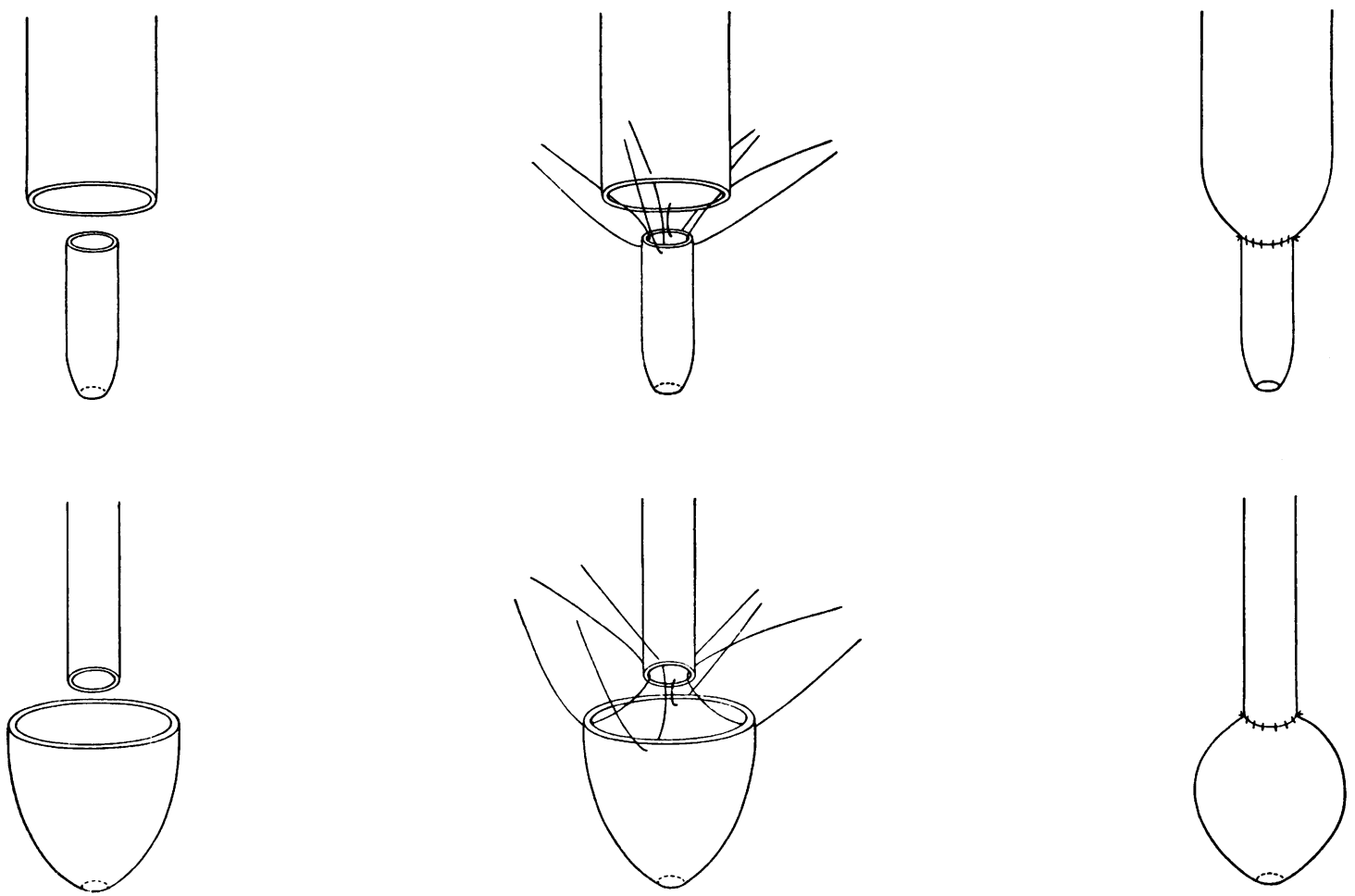

Fig. 3.-Great difference of calibre in common form of Hirschsprung's disease (above), and in megarectum type (below), causes difficulties in anastomosing technique. Surplus of wide lumen must be evenly distributed over narrow lumen.

assumed that this disturbance of co-ordination is part of the whole disease and is also an expression of the defect of the parasympathetic nerve system of the pelvis. This theory of achalasia is an old one. In 1934 Hurst proposed to treat Hirschsprung's disease by dilating the sphincter. The result must however have been poor since nothing was known at that time of the importance of the narrow segment. Dilatation causes rupture of muscle fibres. The strong sphincter closure is weakened and evacuation made easier. The weakening of the sphincter is intended to replace the active relaxation which is lacking. With abdominal pressure the weakened sphincter is overcome passively during defaecation. As we must assume that this achalasia exists in every case of Hirschsprung's disease, we dilated the sphincter immediately after every operation. It soon appeared that the desired effect was not permanent in some cases, especially in infants. Apparently the severity of achalasia varies with different cases. The dilatation had to be repeated several times. From later examinations we ascertained that a powerful sphincter closure had often reappeared. Lasting incontinence has never occurred.

\section{Immediate Post-operative Results}

Most children began to empty their bowels one or two days after the operation and no further measures were necessary. Other cases had to be helped from the start with a flatus tube and enema and it was a long time before they could evacuate on their own. The abdomen became again distended. A tube or the finger need be inserted only a few centimetres and gas and stool are evacuated and the abdomen collapses. Here we are dealing mainly with infants. The colon appears to have no power at all to propel stool in such cases and the slack abdominal walls cannot effect defaecation. But it also happens that, after easy emptying at first, difficulties arise because the anastomosis has a tendency to narrow. These difficulties can be surmounted if daily bouginage with very thick bougies is begun soon after the operation. Thus one can avoid stenosis of the suture and at the same time maintain the effect of sphincter dilatation.

\section{Later Results}

Six of the children on whom we operated died. All were infants. Five deaths had no immediate 

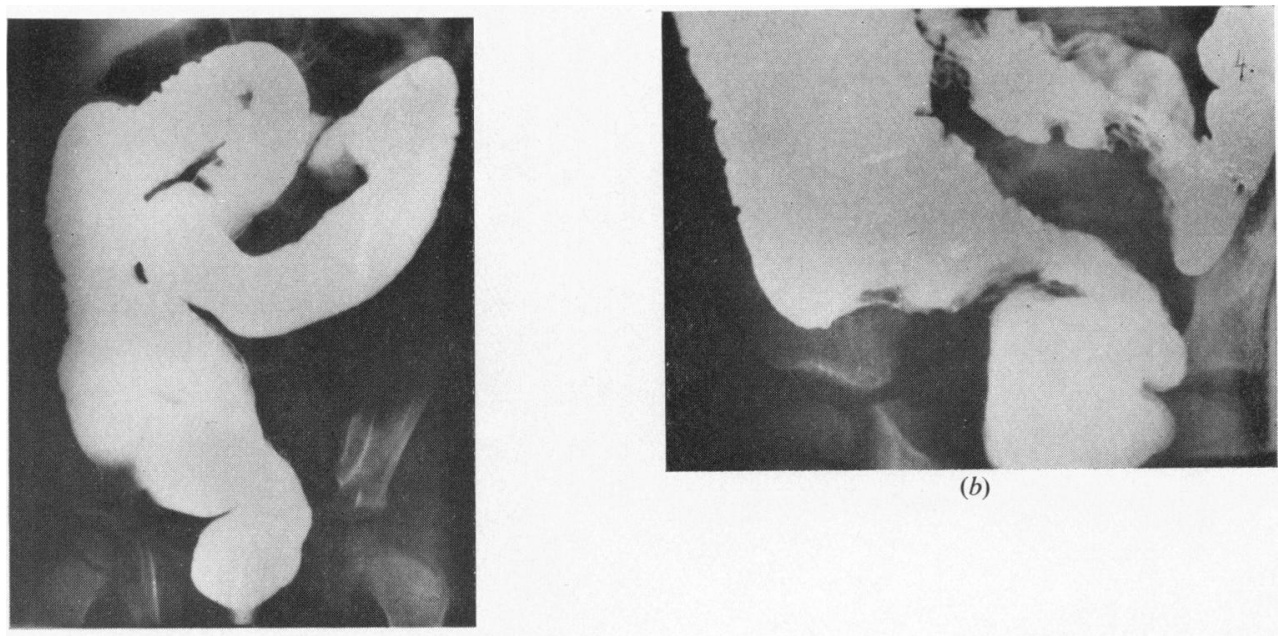

(b)

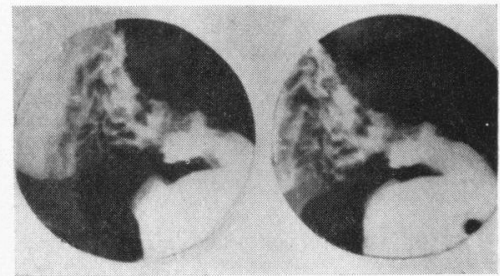

(c)
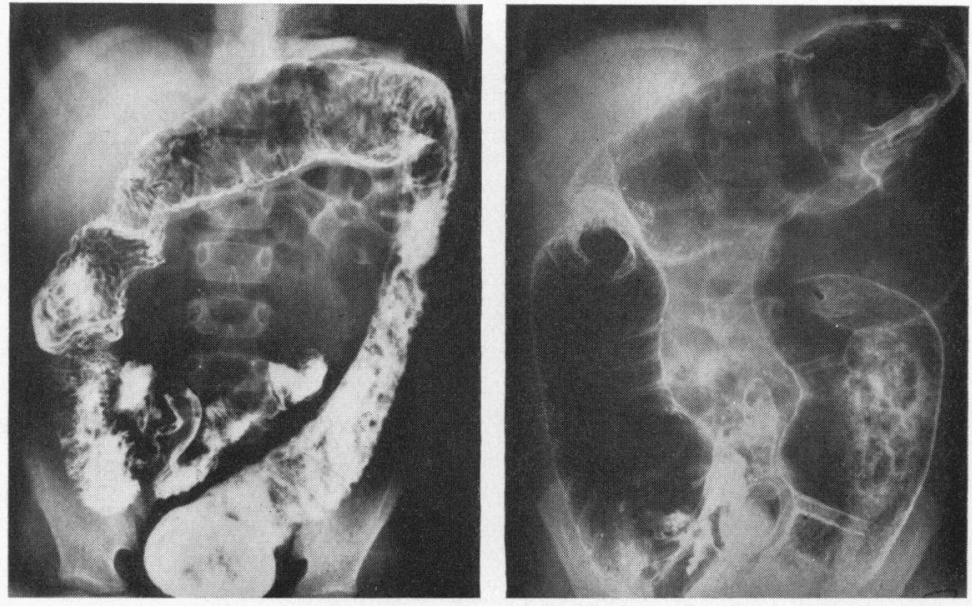

(d)

(e)

FIG. 4.-8-year-old girl with signs typical of Hirschsprung's disease $(a-c)$ operated on five years ago; recurrence of symptoms two years after operation $(d, e)$. Considerable dilatation of large bowel. Remaining rectum wide. 
connexion with the operation. One of the first children died of peritonitis; perforation of the bowel had been caused by bouginage. Another child was found dead in bed at home. The third child died during an operation on an incisional hernia in another hospital. The next died also at home, probably as a result of ileus. Another, in whom a colostomy had been done in the newborn period, died during closure of the colostomy. Only one child died two days after the resection, a 6month-old infant with mongolism.

We have examined many of the children since the operation or received written reports from their parents. Children who have been operated on this year have not been taken into consideration. We have only been able to examine a certain number radiographically. We think, however, that they will suffice to give a picture of the results (Figs. 5-7).

Thirty-seven of the 67 children have been completely relieved of their symptoms (Table 1), they

TABLE 1

RESULTS OF ABDOMINAL RESECTION IN 67 CHILDREN WITH HIRSCHSPRUNG'S DISEASE

\begin{tabular}{|c|c|c|c|c|c|c|}
\hline \multirow[t]{2}{*}{ Year } & \multirow[t]{2}{*}{$\begin{array}{l}\text { No. of } \\
\text { Cases }\end{array}$} & \multicolumn{3}{|c|}{$\begin{array}{c}\text { Laxative, Enema, Abdominal } \\
\text { Distension }\end{array}$} & \multirow[t]{2}{*}{ Died } & \multirow[t]{2}{*}{$\begin{array}{c}\text { No } \\
\text { Response }\end{array}$} \\
\hline & & None & Sometimes & Always & & \\
\hline $1953-58$ & 67 & 37 & 11 & 9 & 6 & 4 \\
\hline
\end{tabular}

need neither enema nor laxatives, they have no abdominal distension and have bowel movements daily. Nine results were poor. The 11 children who are listed in the second group need laxatives and enema occasionally*. A few sometimes show slight abdominal distension. Of course it would still be possible to record a few of these children as good results. Sixteen children empty the bowels once a day; the remaining children do this two or three times daily. Only in some of the cases are the motions solid; usually they are loose. With some children, who had initial difficulties in evacuation, the results have improved with the course of time, whilst others deteriorated some months or even as much as two years after the operation. It may be assumed that from approximately the third year after the operation the results remain steady. It is remarkable that even cases which are clinically completely free of symptoms and seem to be cured still show a certain dilatation of the colon. Wyllie (1957) made the same observation in his children after rectosigmoidectomy. Usually one can still detect the site of anastomosis fairly clearly. The rectum is distended. Cases with noticeable dilata-

\footnotetext{
* Ten of these 20 cases have subsequently become symptom free.
}

tion can also be free of symptoms. The distended bowel is in the stage of compensation. This stage of compensation can last for years and is then practically equivalent to a cure, although the latent possibility of a deterioration or a slow retention of stool may exist in some cases.

\section{Discussion}

Not all cases are equally suitable for abdominal resection. The narrow segment can be situated deep in the rectum, and then anastomosis becomes difficult or impossible; or the narrow segment extends deep into the rectum. In the commonest forms of Hirschsprung's disease, however, when the narrow segment is situated in the rectosigmoid, abdominal resection can achieve good results. The most important thing for the success of the operation is that no obstacles to emptying should remain. No anastomotic stenosis must exist, nor any hindrance to evacuation because of a closure of the anus or a diminished ability to open. None of the narrow segment must be left, but most of the aganglionic rectum must remain. Because on radiological and rectal examination after the operation the rectum is wide, or at least distensible, we cannot believe that the remaining rectum is the cause of any failure. It is not a passive hindrance as is the narrow segment. If evacuation troubles occur, then the sphincter is responsible. Therefore, from this point of view also, a second operation is not necessary.

In rectosigmoidectomy, transitory disturbances of continence occasionally appear as the reports of Swenson (1957), Hiatt (1958a), Wyllie (1957) and others show. This perhaps leads to the conclusion that with dissection of the rectum the achalasia of the sphincter is removed at the same time. A transitory disturbance of continence seems especially favourable with regard to final success. If the bowel can empty itself immediately without any hindrance in the post-operative phase, it has the opportunity to return to normal calibre and is not open to the danger of renewed dilatation. We know that it can return to normal calibre from the colostomy alone. If the sphincter then gradually regains its ability to close, the colon has time to adapt itself functionally to the sphincter. The question of a lasting weakening of the sphincter seems to be the problem with abdominal resection. The function of the sphincter must be permanently weakened so far that continence is just retained. A single dilatation of the sphincter can effect this. But the sphincter has a tendency to regain its ability to close tightly. If that happens, the dilatation must be repeated and it is necessary to continue treatment for some time with 


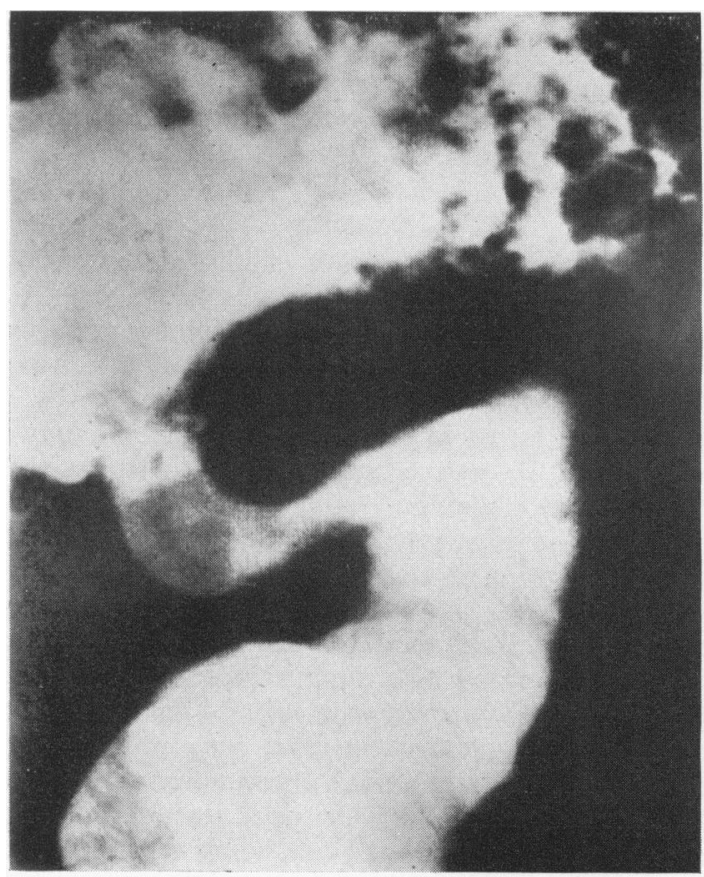

(a)

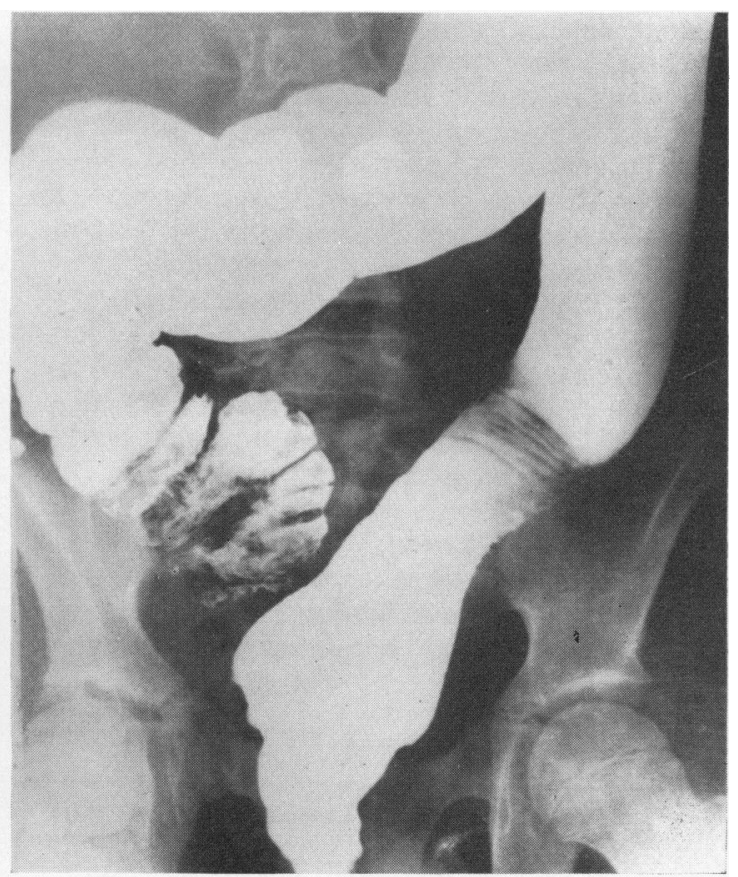

(b)

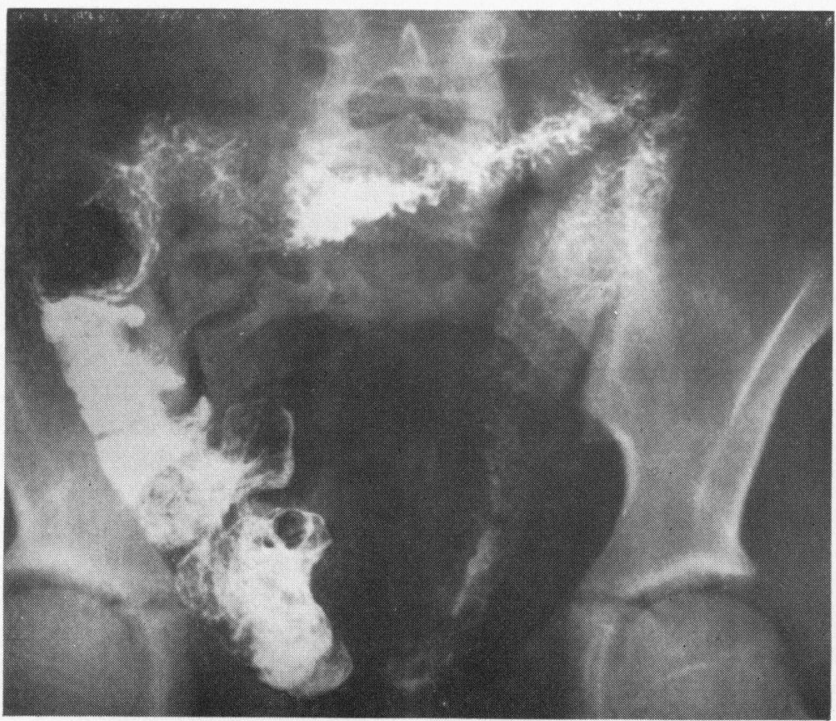

(c)

Fig. 5.-X-ray (a) before, and $(b, c)$ six months after operation on a 19-year-old boy. Large bowel completely filled and showing good emptying. Operation performed five years ago. Full relief of symptoms. 


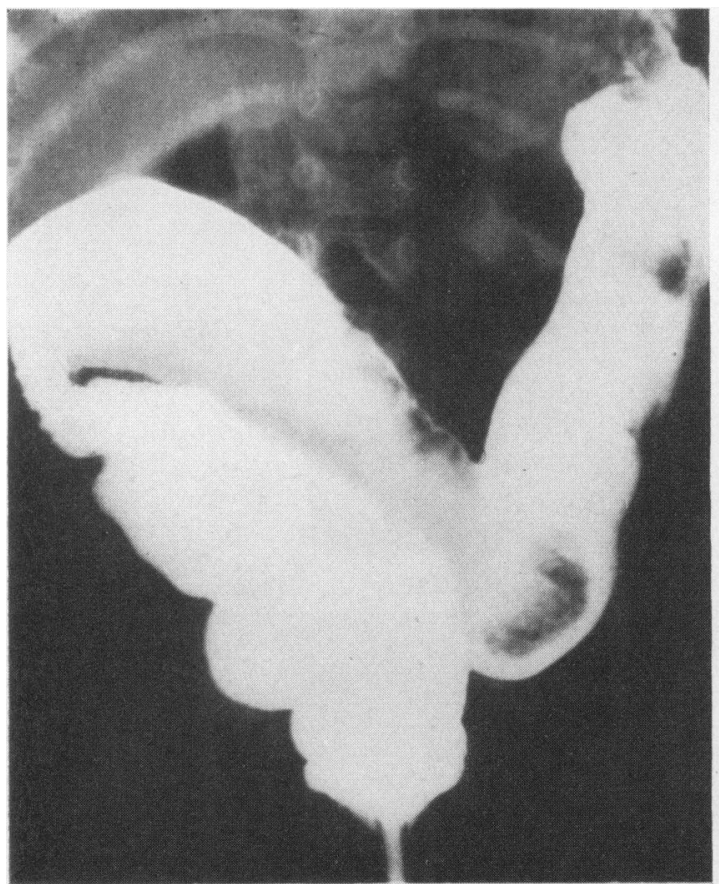

(a)

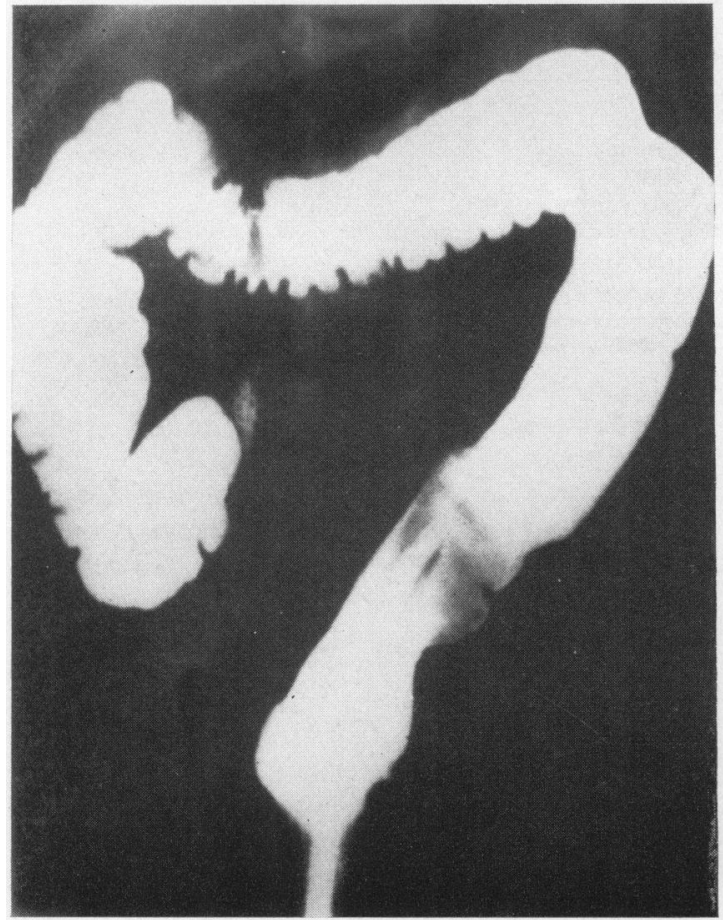

(c)

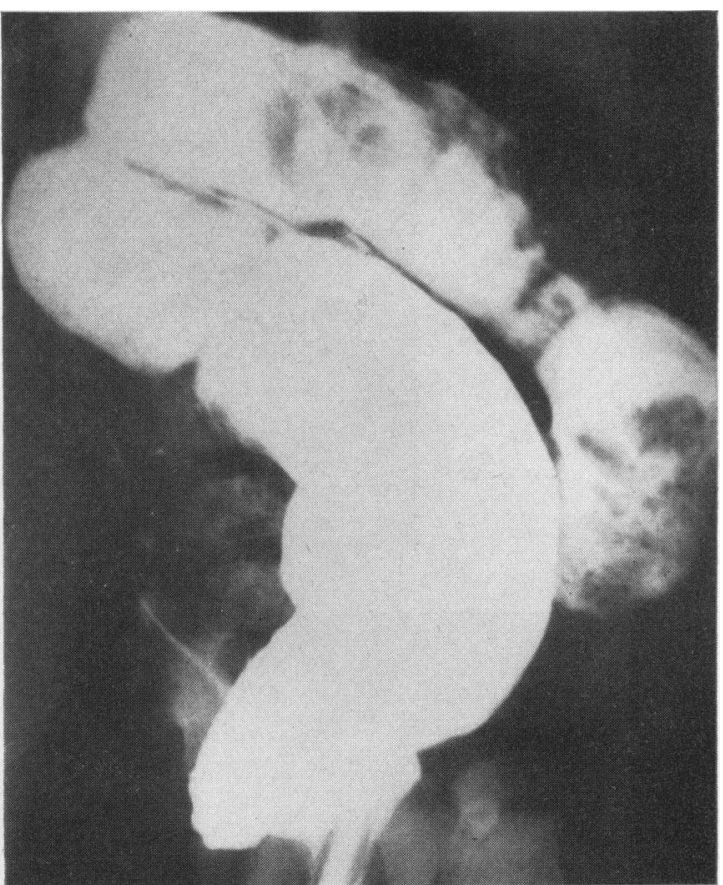

(b)

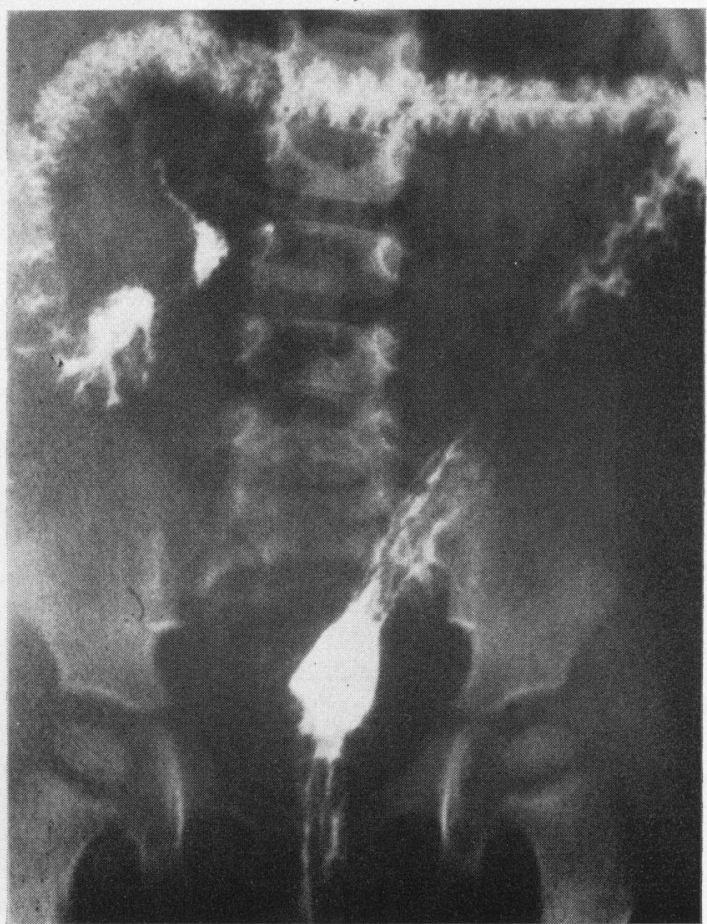

$(d)$

FIG. 6. - $(a, b)$ X-rays of an infant with megarectum type of Hirschsprung's disease; $(c, d)$ follow-up 12 months after operation. Level of anastomosis can be seen. Good emptying. 


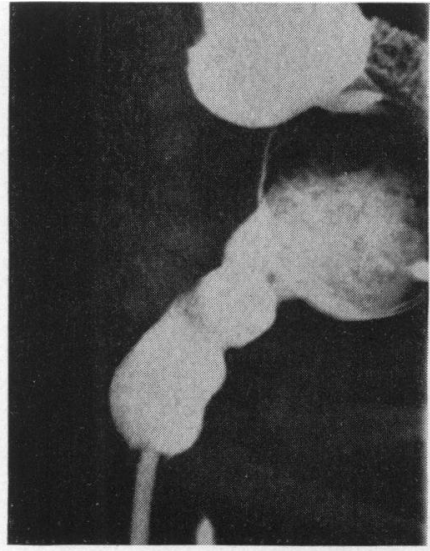

(a)

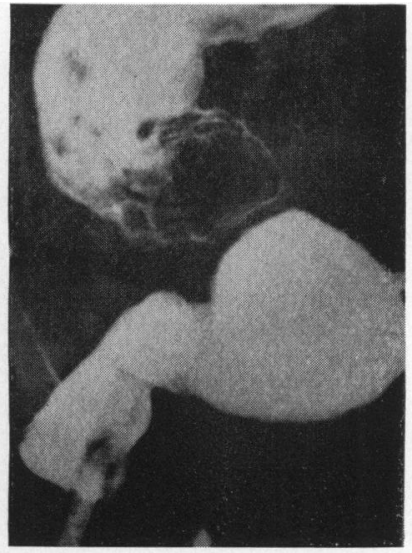

(b)

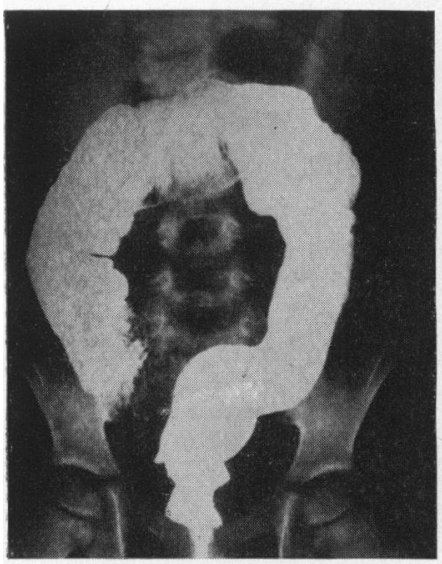

(c)

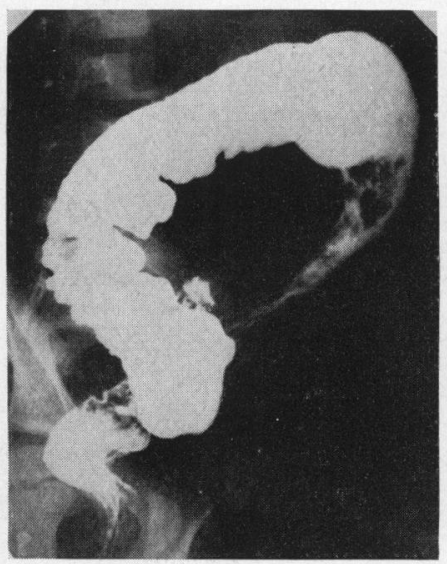

(d)

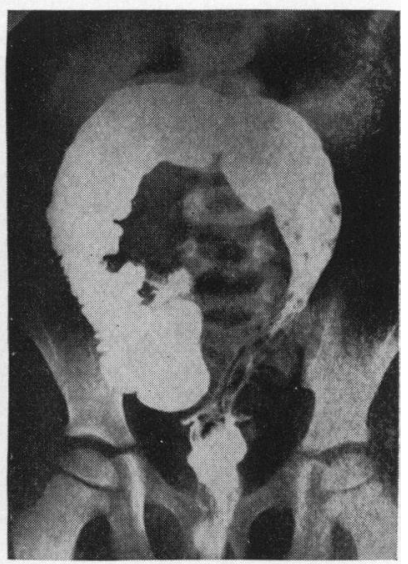

(e)

Fig. 7.-5-year-old boy operated on at 6 months of age. X-rays $(a, b)$ before, and $(c-e)$ four years after operation. Ascending and transverse colon a little more distensible than normal. Satisfactory evacuation of descending colon. Slight diverticula in region of anastomosis. Full relief of symptoms.

thick bougies. The reason why deterioration has been noticed in some of our patients since our 1958 publication (Rehbein, 1958) is to be found in the fact that this systematic treatment, the necessity for which Wyllie (1957) has also pointed out, has not been sufficiently carried out. Up to now this treatment has given us good results in children in whom the earlier results had deteriorated. We may therefore assume that for the other children in the second and third groups of the Table there is still the prospect of a cure. The passage from a good result to renewed constipation can be insidious and unnoticed. If, for example, the emptying of stool no longer takes place daily, or a slight abdominal distension is observed, or even if stool and gas have to be evacuated with the tube from time to time, that is a sign that the bowel is threatening to enter the stage of decompensation. It is necessary to act on these signs in good time.

One must as a rule seek the cause of evacuation difficulties in the anastomosis or in the anus. Only once were we induced to remove the dilated descending colon in an infant during a second operation three months after resection of the sigmoid. The result was good (Fig. 8). In many cases we have resected the colon to the splenic flexure at the beginning. But we are not sure whether that is always necessary. If evacuation cannot take place unhindered, it is of no use however high the resection is.

The treatment of Hirschsprung's disease is most problematical in infancy, but most children are treated at that age. Swenson has for some years limited himself to making a colostomy in infants and 


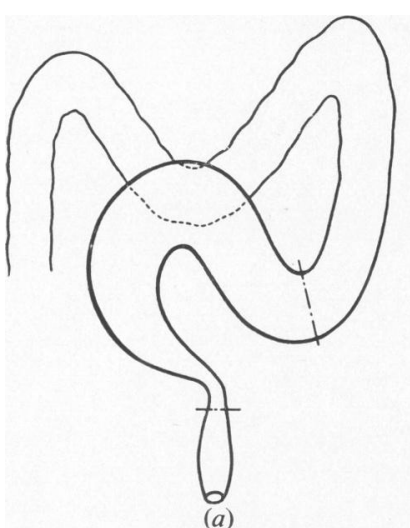

(a)

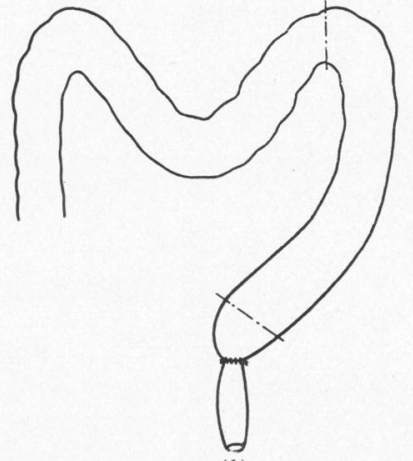

(b)

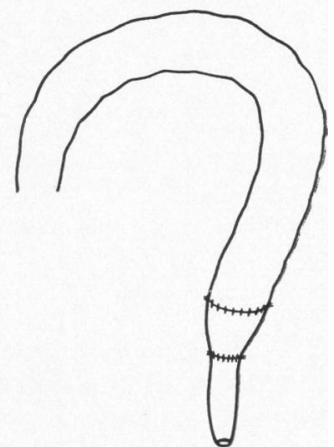

(c)

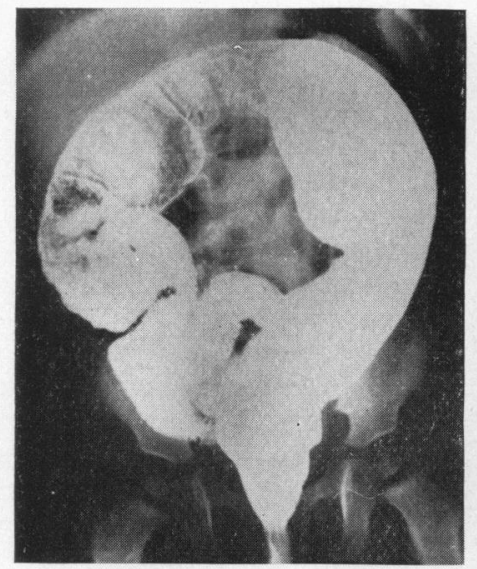

(d)

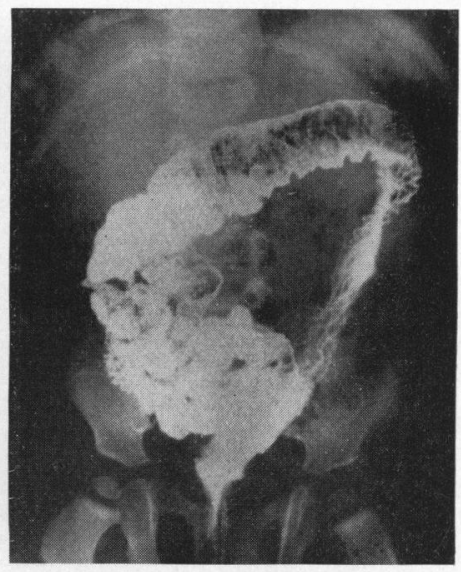

(e)

FIG. 8.-20-month-old boy operated on twice in period of three months. (a-c) diagrams of procedure; $(d, e) \mathrm{X}$-rays seven months after last operation. Free of symptoms.

delaying the resection until the children are 12-18 months old. We have always performed the resection in the first year, and only with ileus in the first weeks of life have we done a colostomy. The future must show which is the better way. But it is the general opinion that operative treatment must take place in infancy. On the other hand, by this early treatment we also receive the serious cases which would have died earlier. So it must be explained that post-operative treatment is more necessary than in older children. In addition these children do not know normal bowel evacuation and do not use abdominal pressure. Stool simply remains in the terminal bowel. One can only treat with the tube, enema, bouginage and laxatives until they have learned spontaneous emptying. If the children are a little older they can help themselves and one can execute bowel training.

We have intentionally indicated the difficulties connected with the application of abdominal re- section. The procedure is smaller and simpler than rectosigmoidectomy but demands intensive postoperative supervision of the child to a higher degree. It is certainly too early for a final picture to be drawn up. The arguments which are raised against the method are not justified in so far as failure lies not in the method but probably in insufficient postoperative treatment. The recurrent necessity for this treatment is a disadvantage compared with rectosigmoidectomy. These difficulties are not insuperable and therefore we see at the moment no reason to depart from this method.

\section{REFERENCES}

Ehrenpreis, T. (1955). Arch. Dis. Childh., 30, 8

Hiatt, R. B. (1958a).Surg. Clin., April, p. 561. - (1958b). Pediatrics, 21, 825.

Hurst, A. F. (1934). Guy's Hosp. Rep., 84, 317.

Rehbein, F. (1958). Chirurg., 29, 366.

State, D. (1952). J. Amer. med. Ass., 149, 350.

Swenson, O. (1957). Ann. Surg., 146, 706.

- and Bill, A. H. (1948). Surgery, 24, 212

Thomas, C. G. (1958). Amer. Surg., 24, 630.

Wyllie, G. G. (1957). Lancet, 1, 850. 